\title{
PREDICTION OF ADSORPTION EFFICIENCY FOR THE REMOVAL MALACHITE GREEN AND ACID BLUE 161 DYES BY WASTE MARBLE DUST USING ANN
}

\author{
ÇORUH S. ${ }^{1, *}$ \\ GÜRKAN H.E. ${ }^{1}$ \\ KILIC E. ${ }^{2}$ \\ GEYIKCI F.
}

\author{
${ }^{1}$ Ondokuz Mayis University \\ Environmental Engineering Department, Samsun, Turkey \\ ${ }^{2}$ Ondokuz Mayis University \\ Computer Engineering Department, Samsun, Turkey \\ ${ }^{3}$ Ondokuz Mayis University \\ Chemical Engineering Department, Samsun, Turkey
}

*to whom all correspondence should be addressed:

\section{ABSTRACT}

In the present study, batch adsorption studies were performed for the removal of malachite green and acid blue 161 dyes from aqueous solutions by varying parameters such as contact time, waste marble dust amount, initial dye concentration and temperature. The equilibrium adsorption data were analyzed by Langmuir, Freundlich and Temkin adsorption isotherm models. The Langmuir and Freundlich adsorption models agree well with experimental data. The pseudo-second order, intraparticle intraparticle diffusion and Elovich kinetic models were applied to the experimental data in order to describe the removal mechanism of dye ions by waste marble dust. The pseudo-second order kinetic was the best fit kinetic model for the experimental data. Thermodynamics parameters such as $\Delta G, \Delta H$ and $\Delta S$ were also calculated for the adsorption processes. The experimental data were used to construct an artificial neural network (ANN) model to predict removal of malachite green and acid blue 161 dyes by waste marble dust. A three-layer ANN, an input layer with four neurons, a hidden layer with 12 neurons, and an output layer with one neuron is constructed. Different training algorithms were tested on the model to obtain the proper weights and bias values for ANN model. The results show that waste marble dust is an efficient sorbent for malachite green dye and ANN network, which is easy to implement and is able to model the batch experimental system.

Keywords: Waste marble dust, adsorption, malachite green, acid blue, ANN

\section{Introduction}

Dyes are significant pollutants causing environmental and health problems. Most industries use dyes and pigments to color their products. Today more than 9000 types of dyes have been incorporated in the color index and the biggest consumers of these dyes are textile, tannery, paper and pulp industry, cosmetic, plastics, coffee pulping, pharmaceuticals, food processing, electroplating and distilleries spew, perhaps these are the serious polluters of our environment as far as color pollution is concerned. Due to its complex chemical structure, dye is one of the most difficult constituents in the textile wastewater to treat. The treatment of dye house wastewater constitutes major economical and environmental issues (Thinakaran et al., 2006; Rastogi et al., 2008; Mahmoued, 2010; Alver and Metin 2012). Most of the dyes are stable and has no effect of light or oxidizing agents. They are also not easily degradable by the conventional treatment methods. Removal of dyes from the effluent is a major problem in most of the textile industries. Several biological, physical and chemical methods have been used for the treatment of 
the industrial textile wastewater including microbial biodegradation, membrane, coagulation, filtration, complexation, biosorption, oxidation and ozonation. However, most of the above methods suffer from one or more limitations and none of them were successful in completely removing the color from wastewater (Dawood, 2010; Mahmoued, 2010; Nethaji et al., 2010). Among these methods, adsorption process is one of the effective methods for removal dyes from waste influent. Adsorption has been found to be superior to other techniques for water re-use in terms of initial cost, simplicity of design, ease of operation and insensitivity to toxic substances (Luo et al., 2010; Jayaraj et al., 2011; Rahman et al., 2013). Activated carbon has been used widely in many adsorption applications due to its high adsorption capacity yet commercially activated carbon is expensive. Therefore, many researchers try to search for a low-cost adsorbent substitutable for activated carbon. A low-cost adsorbent is defined as one which is abundant in nature, or is a byproduct or waste material from another industry. Many lowcost adsorbents have been searched by investigators to substitute it. Studies so far have focused on adsorbents such as alumina, magnetite, silica, goethite, bentonite, activated carbon, clay, perlite, zeolite, sawdust, banana and orange peels, fly ash, red mud, waste marble dust, tea industry waste, coffee bean, cement kiln dust, bagasse fly ash, phosphogypsum, sepiolite, bentonite, kaolinite and others (Ahlawat, 2008; Rastogi et al., 2008; Lian et al., 2009; Baek et al., 2010; Dawood, 2010; Mahmoued, 2010, Rahman et al., 2013).

Many rich marble deposits in countries like Portugal, Spain, Italy, Eqypt, Greece, Turkey, Iran and Pakistan are located in Alpine-Himalayan belt. Turkey has numerous marble deposits. Turkey has even more, $40 \%$ of total marble reserves in the world. Seven million tons of marble are produced in Turkey annually. In processing marble such as cutting to size and polishing etc. for decorative purposes, marble dust and aggregate are created as byproducts (Celik and Sabah 2008, Gencel et al., 2012). The byproduct generated from marble processing is a powdered dust and may represent an environmental problem. At this moment, most of the marble waste is landfilled and alternative solutions are being explored in many countries with the aim to turn marble waste into a sustainable material (Bacarji et al., 2013).

An ANN is a self-adaptive method and has the ability to approximate any reasonable function arbitrarily well. The leraning and generalization ability of an ANN makes it a powerful modelling tool (Haykin, 1999). In the past, ANNs have been successfully employed in the modelling of several processes such as those conducted (Prakash et al., 2008; Yetilmezsoy and Demirel, 2008; Raj et al., 2010; Aber et al., 2009; Sadrzadeh et al., 2008; Elemen et al., 2012; Sinha et al., 2012) The main advantage of the ANN model over traditional methods is that they do not require the complex nature of the underlying process. This modelling tool has not been used yet to model the adsorption of dyes by waste marble dust.

The aim of this study is to evaluate adsorption kinetics, isotherms and thermodynamic parameters of malachite green and acid blue 161 dyes from aqueous solution using waste marble dust. The different parameters influencing the adsorption of malachite green dye ions on marble wastes were optimized and the results are presented in this paper. Also in this work, experimental data were modeled by an ANN to predict removal malachite green and acid blue 161 dyes by waste marble dust.

\section{Experimental Procedure}

\subsection{Adsorbent}

The waste marble dust sample used in this study was obtained in wet form as an industrial by product in istanbul region. The wet waste marble dust was dried up prior to the preparation of the samples. The samples were sievied and those with size $(90-125 \mu \mathrm{m})$ were used in the experiments. The waste marble dust contains the chemical compounds $\mathrm{SiO}_{2}, \mathrm{Al}_{2} \mathrm{O}_{3}$, and $\mathrm{CaO}$ with minor contents of $\mathrm{MgO}, \mathrm{Fe}_{2} \mathrm{O}_{3}, \mathrm{~K}_{2} \mathrm{O}$ and $\mathrm{Na}_{2} \mathrm{O}$ according to XRD analysis. The physical properties and chemical constituents of marble waste is given in Table 1. The crystalline phase composition of the waste marble dust used in this work was characterized by SEM (FEI Quanta 400 MK2) in Fig. 1. 
Table 1. Chemical composition (wt. \%) of waste marble dust

\begin{tabular}{cc}
\hline & Cement kiln dust \\
\hline $\mathrm{SiO}_{2}$ & 13.40 \\
\hline $\mathrm{Fe}_{2} \mathrm{O}_{3}$ & 1.80 \\
\hline $\mathrm{Al}_{2} \mathrm{O}_{3}$ & 3.30 \\
\hline $\mathrm{CaO}$ & 43.40 \\
\hline $\mathrm{K}_{2} \mathrm{O}$ & 0.70 \\
\hline $\mathrm{MgO}$ & 1.20 \\
\hline $\mathrm{Na}_{2} \mathrm{O}$ & 0.20 \\
\hline $\mathrm{MnO}$ & 0.10 \\
\hline $\mathrm{TiO}_{2}$ & 0.20 \\
\hline $\mathrm{LOI}^{*}$ & 35.70 \\
\hline
\end{tabular}

"Loss on ignition

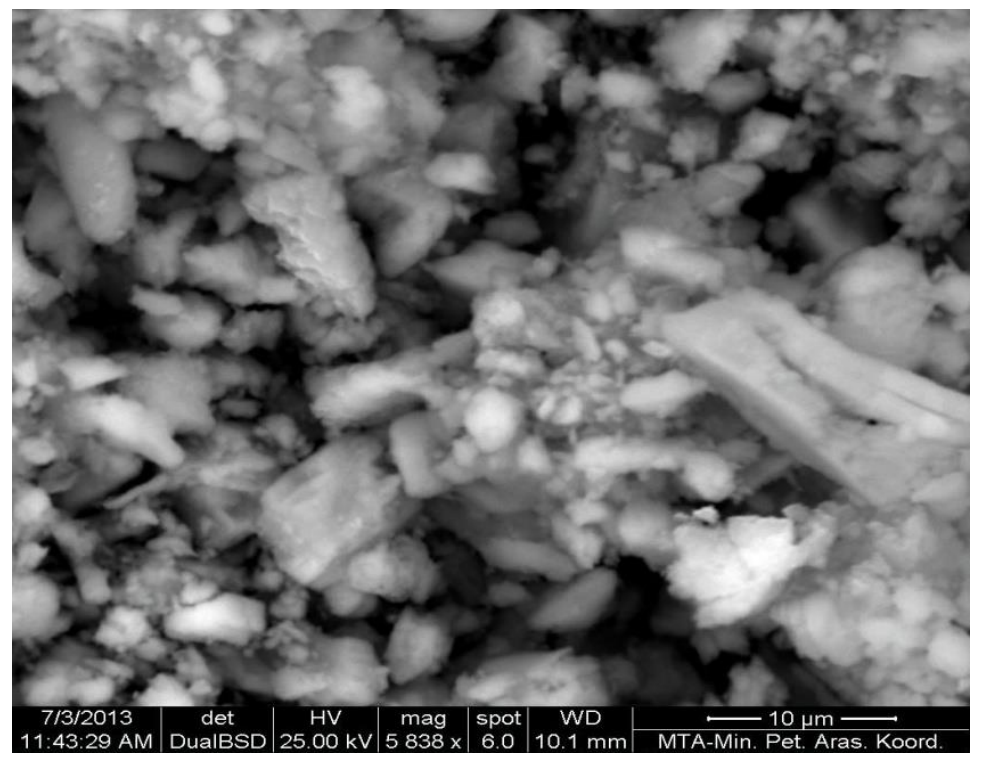

Figure 1. SEM spectrum of waste marble dust

\subsection{Adsorbate}

The textile dyes; malachite green $\left(\mathrm{C}_{23} \mathrm{H}_{26} \mathrm{ClN}_{2}\right)$, acid blue $161\left(\mathrm{C}_{20} \mathrm{H}_{13} \mathrm{~N}_{2} \mathrm{O}_{5} \mathrm{SNaCr}_{\mathrm{x}}\right)$ were selected for adsorption studies. The stock solution of $1000 \mathrm{mg} \mathrm{I}^{-1}$ was prepared by dissolving accurately weighed amounts of malachite green and acid blue 161 in $1000 \mathrm{ml}$ distilled water. Table 2 shows some properties of textile dyes. The initial $\mathrm{pH}$ of solutions was adjusted to the required value by using $\mathrm{NaOH}$ or $\mathrm{HCl}$ solutions. Malachite green and acid blue 161 concentrations were analyzed by measuring the absorbance values after and before each experiment at $620 \mathrm{~nm}$ and $341 \mathrm{~nm}$, respectively.

\subsection{Adsorption procedure}

In order to determine the effect of contact time, initial dye concentration, adsorbent dosage, $\mathrm{pH}$ and adsorption temperature on malachite green and acid blue 161 dye removal efficiency, batch experiments were conducted. A stock solution $1000 \mathrm{mg} \mathrm{l}^{-1}$ of dye was prepared in distilled water and was diluted according to the working concentration. Thermo 10- UV/Visible Spectrophotometer was used at $\lambda_{\max }$ of $620 \mathrm{~nm}$ for malachite green and at $\lambda_{\max }$ of $341 \mathrm{~nm}$ for acid blue 161 to make the absorbance measurements. The dye solution $(50 \mathrm{~mL})$ at desired concentration $\left(12.5\right.$ and $\left.200 \mathrm{mg} \mathrm{I}^{-1}\right)$, adsorbent dosage $\left(1.25\right.$ and $\left.20 \mathrm{~g} \mathrm{I}^{-1}\right)$, adsorption tempature $\left(20^{\circ} \mathrm{C}\right.$ and $\left.70{ }^{\circ} \mathrm{C}\right)$ and contact time $(5$ and 
$240 \mathrm{~min}$ ) taken in $250 \mathrm{~mL}$ erlanmayer flasks was used. $\mathrm{pH}$ value of distilled water ( $\mathrm{pH} \mathrm{6.25)} \mathrm{for} \mathrm{all}$ adsorption experiments was used. The flasks were kept under agitation in a rotating shaker at $150 \mathrm{rpm}$ for $1 \mathrm{~h}$. The removal efficiency (E) of the waste marble dust on malachite green and acid blue 161 dye was calculated according to the following formula:

$E(\%)=\frac{C_{0}-C}{C_{0}} \times 100$

where $C_{0}$ is the initial concentration of the dye solution and $C$ is the final concentration of the dye solution.

Table 2. Some properties of malachite green and acid blue 161

\begin{tabular}{ccc}
\hline Textile Dyes Properties & Malachite green & Acid Blue 161 \\
\hline C.I. No & 42000 & 15706 \\
\hline CAS No & $5596-64-2$ & $12392-64-2$ \\
\hline Chemical Formula & $\mathrm{C}_{23} \mathrm{H}_{26} \mathrm{ClN}_{2}$ & $\mathrm{C}_{20} \mathrm{H}_{13} \mathrm{~N}_{2} \mathrm{O}_{5} \mathrm{SNaCr}_{\mathrm{X}}$ \\
\hline Molecular Weight & 364.92 & Bcid Dye \\
\hline C.I. Name & Basic Dye & AI
\end{tabular}

\subsection{Modeling Approach}

In literature, many ANN architectures have been used to model engineering problems. The most widely used ANN models among feed-forward models, are the Multi-Layer Perceptron (MLP) and the Radial Basis Function (RBF) models (Haykin, 1999; Elemen et al., 2012; Sinha et al., 2012).

In this study, an ANN was used to predict the percentage of the malachite green or acid blue 161 dyes removal. For this purpose, a three-layer ANN, an input layer with four neurons (e.g. contact time, waste marble dust amount, initial dye concentration and temperature), one hidden layer with 12 neurons, and an output layer with one neuron (e.g. malachite green and acid blue 161 dyes) (4-12-1) is constructed. Different training algorithms are tested on the model proposed to obtain the best weights and bias values for the model. After, the four-layer ANN is evaluated by using the weights and bias values obtained the best training algorithm.

\subsection{The ANN Model}

In this study a feed-forward MLP with logaritmic sigmoid transfer function (logsig) at hidden layer and output layer was used. Different BP algorithms were compared to select the best suited BP algorithm. The gradient descent bacprobagation with adaptive learning rate algorithm was found as the best. The model and its parameters were determined based on the minimum value of the mean squared error (MSE) of the training and prediction set.

The training and testing data is obtained from the experimental studies. The training data set consists of 40 data items and the validation set consists of 6 data items and the testing data set consists of 8 data item. The range of training, validation, and testing data is shown in Fig.2, Fig.3, Fig.4, and Fig.5, respectively. A small amount of data causes over-fitting problems during neural network training process. The network has memorized the training examples, but it has not learned to generalize to new situations. To avoid this problem a validation data set was used in this study.

If the proposed ANN model is not valid due to transfer functions, other type of transfer functions can be used. If you need more data new experiments should be carried out. The Neural Network Toolbox of Matlab R2011 mathematical software was employed. 


\section{Results and discussion}

\subsection{Effect of particle size}

To evaluate the effect of particle size on adsorption process, the samples were sieved into the following particle sizes $(\mu \mathrm{m}):-500+250,-250+125,-125+90$, and $-90+60$. The adsorption characteristics of waste marble dust with respect to particle sizes are given Fig 2. Fig shows that decreasing in particle size of waste marble dust causes an little increase adsorption loading and adsorption efficiency. Therefore, increase in removal efficiency with decrease in particle size of waste marble dust is not significant.

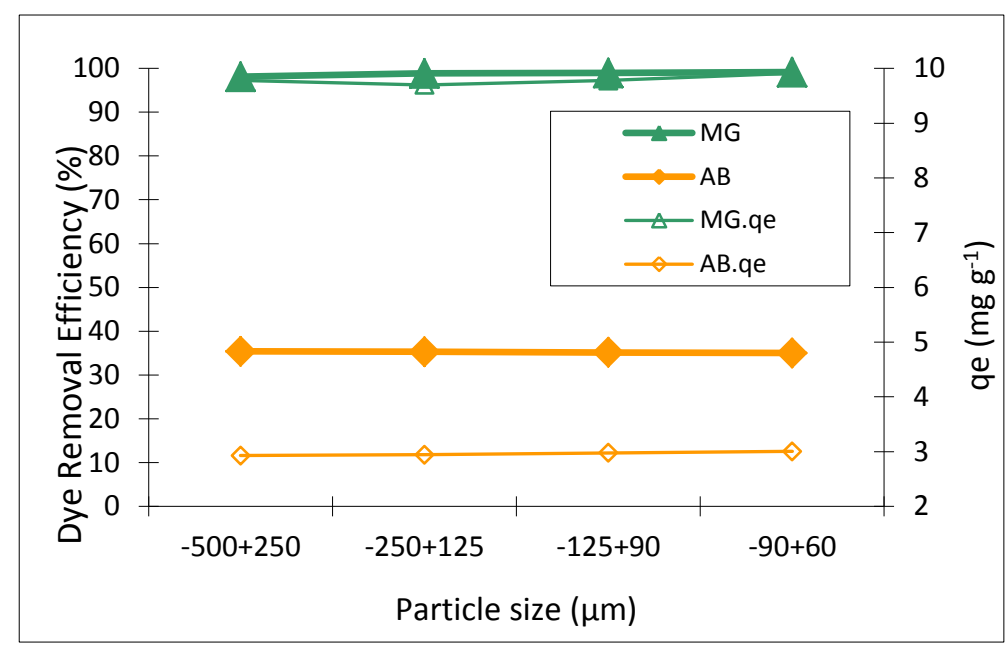

Figure 2. Effect of particle size on malachite green and acid blue 161 adsorption

$$
\text { ( } \mathrm{T}: 20^{\circ} \mathrm{C}, \mathrm{C}_{\mathrm{o}}: 50 \mathrm{mg} \mathrm{l}^{-1} \text {, dosage: } 5 \mathrm{~g} \mathrm{I}^{-1} \text { ) }
$$

\subsection{Effect of contact time on the removal of malachite green and acid blue 161}

The effects of contact time in the range 5-240 min were studied using a constant concentration of malachite green and acid blue 161 dye solution at $20^{\circ} \mathrm{C}$. The removal percentages of the malachite green and acid blue 161 dyes as a function of contact time are shown in Fig 3.

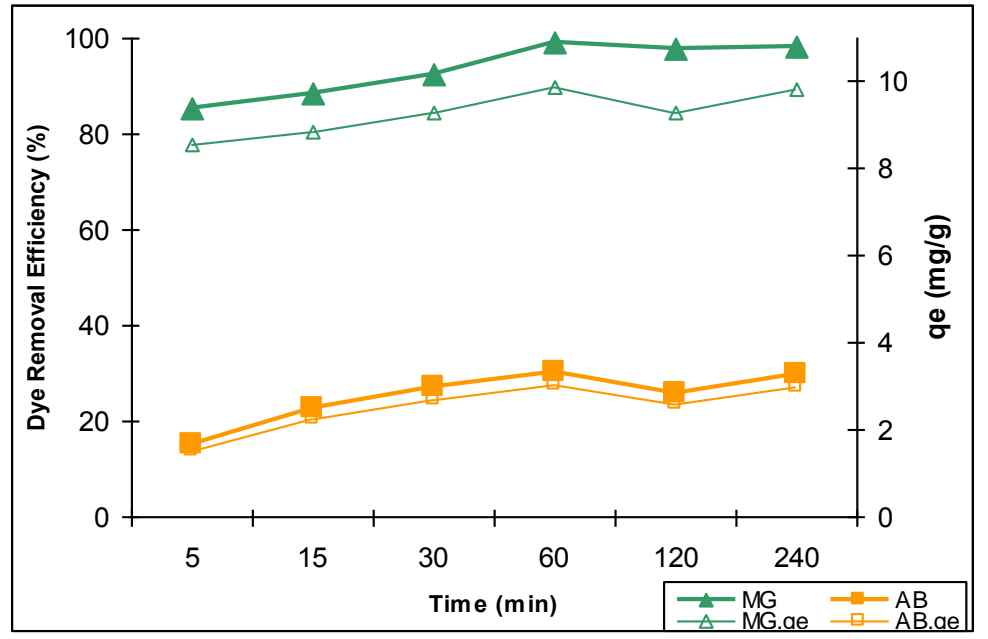

Fig. 3. Effect of contact time on malachite green and acid blue 161 adsorption

$$
\text { ( } \mathrm{T}: 20^{\circ} \mathrm{C}, \mathrm{C}_{\mathrm{o}}: 50 \mathrm{mg} \mathrm{l}^{-1} \text {, dosage: } 5 \mathrm{gl}^{-1} \text { ) }
$$

The results showed that the removal of malachite green and acid blue 161 dye increases with time rapidly and saturation in about $120 \mathrm{~min}$. The results clearly show that if contact time for waste waste marble dust is increased from 5 to 120 minutes, the removal efficiencies for malachite green and acid blue 161 dye increase from $85.33 \%$ to $98.18 \%$ and $15.29 \%$ to $29.65 \%$, respectively. However, the adsorption of acid blue 161 dye using waste marble dust is very limited due to the surface of the waste 
marble dust and dye molecules having negative charges. It is know that waste marble dust has a negative charged surface, this causes a relatively low adsorption capacity for acidic dyes. As can be seen in Fig.3. malachite green dye have more effective dye than acid blue 161 dye for waste marble dust (Crini, 2006; Kuleyin and Aydin, 2011; Alver and Metin, 2012).

\subsection{Effect of waste marble dust amount on the removal of malachite green and acid blue 161}

Fig. 4 shows the effect of the amount of waste marble dust dosage on the malachite green and acid blue 161 removal. As the waste marble dust amounts increased, the removal efficiencies increased. The removal efficiencies for $0.125 \mathrm{~g} \mathrm{I}^{-1}$ of waste marble dust for malachite green and acid blue 161 were found to be $98.78 \%$ and $99.68 \%$, but as the waste marble dust amounts were increased to $2 \mathrm{~g} \mathrm{l}^{-1}$, removal efficiencies were found to be $2.47 \%$ and $48.91 \%$. These results show that removal efficiency was increased with increasing amount of the waste marble dust.

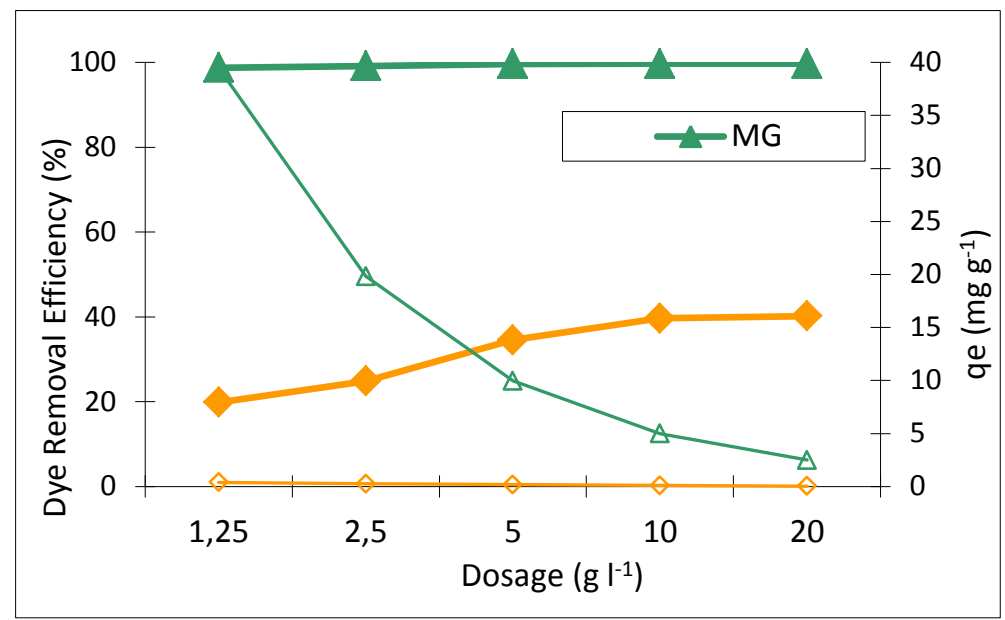

Figure 4. Effect of waste waste marble dust amount on malachite green and acid blue 161 adsorption ( $\mathrm{T}: 20^{\circ} \mathrm{C}, \mathrm{C}_{\mathrm{o}}: 50 \mathrm{mg} \mathrm{l}^{-1}$, time: $1 \mathrm{~h}$ )

\subsection{Effect of initial dye concentration of malachite green and acid blue 161}

The effects of initial malachite green and acid blue 161 concentrations in the range of $12.5-200 \mathrm{mg} \mathrm{I}^{-1}$ on the adsorption were investigated under the specified conditions.

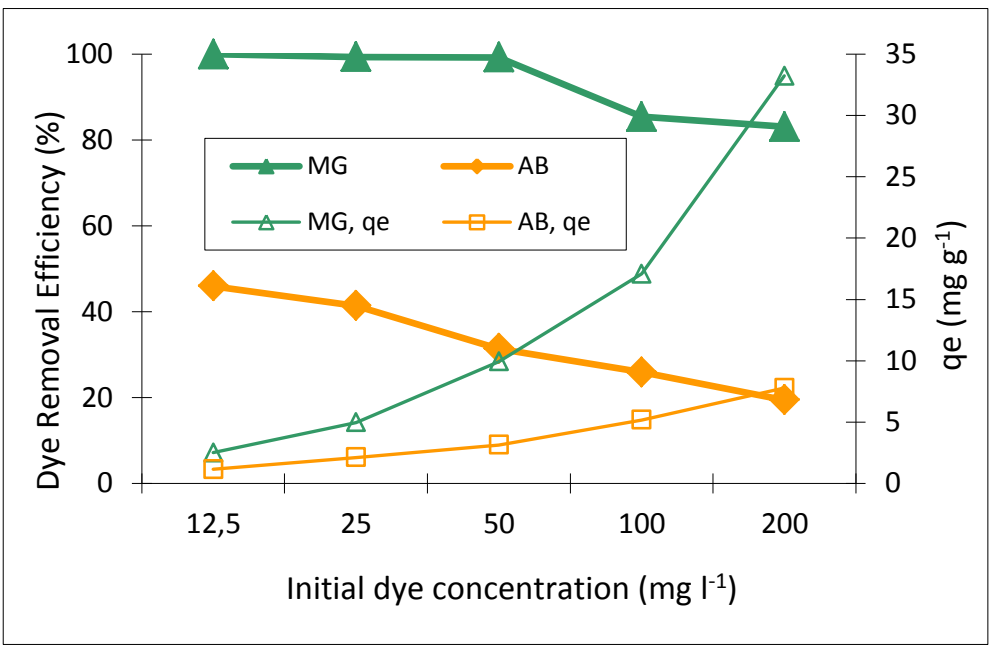

Figure 5. Effect of initial concentration on malachite green and acid blue 161 adsorption ( $\mathrm{T}: 20^{\circ} \mathrm{C}$, dosage: $5 \mathrm{~g} \mathrm{I}^{-1}$, time: $1 \mathrm{~h}$ )

Fig. 5 shows the adsorption of malachite green and acid blue 161 on waste waste marble dust as an initial dye concentration. The percent adsorption of malachite green and acid blue 161 are inversely 
related to the initial dye concentrations. Percentage of malachite green and acid blue 161 removal decreased as its concentration increased at fixed adsorbent dosage. As can be seen from Fig. 5, increasing the dye concentration led to an increase in the dye adsorption by waste marble dust. This can be attributed to the effective pore diffusivity decrease with increasing initial dye concentration. The maximum adsorption capacity of waste waste marble dust was found to be $33.23 \mathrm{mg} \mathrm{g}^{-1}$ for $200 \mathrm{mg} \mathrm{l}^{-1}$ MG dye concentration and $7.77 \mathrm{mg} \mathrm{g}^{-1}$ for $200 \mathrm{mg} \mathrm{l}^{-1} \mathrm{AB} 161$.

\subsection{Effect of temperature on the removal of malachite green and acid blue 161}

The effect of temperature on the malachite green and acid blue 161 adsorption on waste waste marble dust was carried out at 20,30, 50 and $70{ }^{\circ} \mathrm{C}$. The results are presented in Fig. 6 From the Fig. 6, the removal of malachite green and acid blue 161 was slightly increases with temperature, which indicates the endothermic nature of the adsorption reaction. At higher temperature, more dye molecules have sufficient energy to undergo an interaction with active sites at the surface. In addition, increasing the temperature was known to increase the rate of diffusion of the adsorbate molecules across the external boundary layer and in the internal pores of the adsorbent particle due to the decrease in the viscosity of the solution (Nethaji et al., 2010; Alver and Metin, 2012).

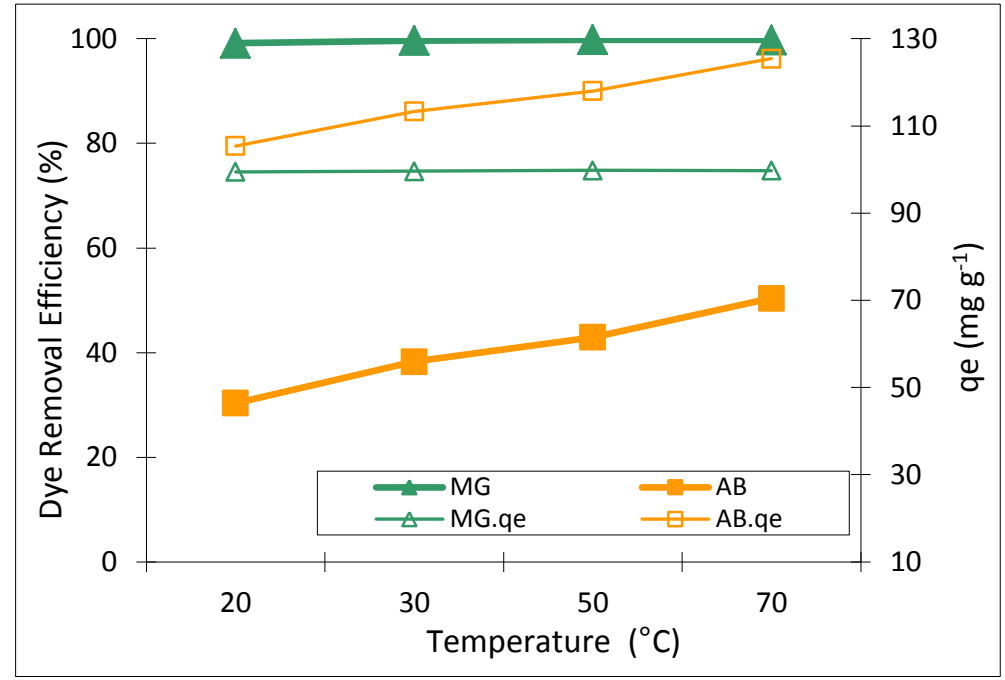

Figure 6. Effect of temperature on malachite green and acid blue 161 adsorption on waste waste marble dust $\left(C_{0}: 50 \mathrm{mg}^{-1}\right.$, dosage $: 5 \mathrm{gl}^{-1}$, time: $\left.1 \mathrm{~h}\right)$

\subsection{Adsorption isotherm models}

The successful representation of the dynamic adsorptive seperation of solute from solution on an adsorbent depends upon a good description of the equilibrium separation between the two phases. An adsorption isotherm is characterized by certain constant values, which express the surface properties and affinity of the adsorbent and can also be used to compare the adsorptive capacities of the adsorbent for different pollutants (Nuhoglu and Malkoc, 2009). The effect of concentration on sorption was applied to different isotherm models to find a suitable model to instruct the further experimental design. Several isotherm equations are available. In this research, in order to determine the mechanism of $\mathrm{MB}$ and $\mathrm{CV}$ adsorption on the waste waste marble dust the experimental data was applied to the Langmuir, Freundlich, Temkin isotherm equations (Bulut, et al., 2008; Ahmad and Alrozi, 2011).

The Langmuir sorption isotherm is the best known of all isotherms describing sorption and it has been successfully applied to many sorption processes. Thus, the Langmuir isotherm model is given by equation (Hui et al., 2005; Oren and Kaya, 2006);

$\frac{C_{e}}{q_{e}}=\frac{1}{q_{m} K_{L}}+\frac{C_{e}}{q_{m}}$ 
where $q_{e}$ is the equilibrium adsorbed $\left(\mathrm{mg} \mathrm{g}^{-1}\right), C_{e}$ is the equilibrium liquid-phase concentration $\left(\mathrm{mg} \mathrm{l}^{-1}\right)$, $\mathrm{q}_{\mathrm{m}}$ and $\mathrm{K}_{\mathrm{L}}$ are the Langmuir constants related to sorption capacity and sorption energy, respectively. The values of $q_{m}\left(\mathrm{mg} \mathrm{g}^{-1}\right)$ and $K_{L}\left(\mathrm{mg}^{-1}\right)$ can be determined from the linear plot of $C_{e} / q_{e}$ versus $C_{e}$ (Fig. 7a). The values $\mathrm{q}_{\mathrm{m}}$ and $\mathrm{K}_{\mathrm{L}}$ obtained from these plots are listed in Table 3.

Table 3. Constants of adsorption of MG and $A B$ uptake by waste waste marble dust

\begin{tabular}{ccccccccccc}
\hline \multirow{2}{*}{ Dye } & \multicolumn{3}{c}{ Langmuir } & \multicolumn{3}{c}{ Freundlich } & \multicolumn{3}{c}{ Temkin } \\
\cline { 2 - 11 } & $\mathbf{q m}$ & $\mathrm{K}_{\mathrm{L}}$ & $\boldsymbol{R}^{\mathbf{2}}$ & $\mathbf{K}_{\mathrm{f}}$ & $\mathbf{n}$ & $\boldsymbol{R}^{\mathbf{2}}$ & $\mathbf{A}$ & $\mathbf{B}$ & $\boldsymbol{R}^{\mathbf{2}}$ \\
\hline MG & 4.67 & 0.883 & 0.9888 & 9.45 & 4.438 & 0.9568 & 258.70 & 2.7146 & 0.7465 \\
\hline AB 161 & 10.62 & 0.0150 & 0.9636 & 0.39 & 1.693 & 0.9929 & 0.20 & 2.0371 & 0.9467 \\
\hline
\end{tabular}

The Freundlich isotherm is an empirical model that is based on adsorption on heteregenous surface; it is given in Eq. (3),

$\log q_{e}=\log K+(1 / n) \log C_{e}$

where $q_{e}$ the amount of dye ions adsorbed per gram of adsorbent at equilibrium $\left(\mathrm{mg} \mathrm{g}^{-1}\right), C_{e}$ is the equilibrium concentration in $\mathrm{mg}^{-1}, K$ is roughly an indicator of the adsorption capacity $\left(\mathrm{mg} \mathrm{g}^{-1}\right), n$ is a characteristic constant for the adsorption system $\left(\mathrm{I} \mathrm{g}^{-1}\right)$.

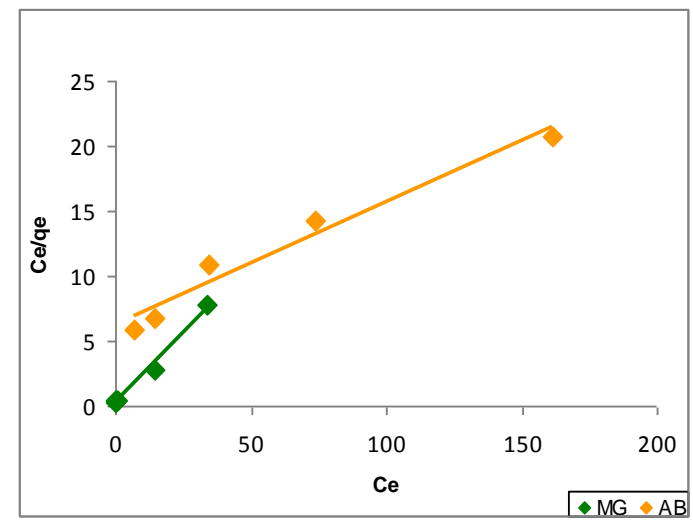

Figure 7a. The Linearized Langmuir isotherm of MG and $A B 161$ uptake by waste waste marble dust

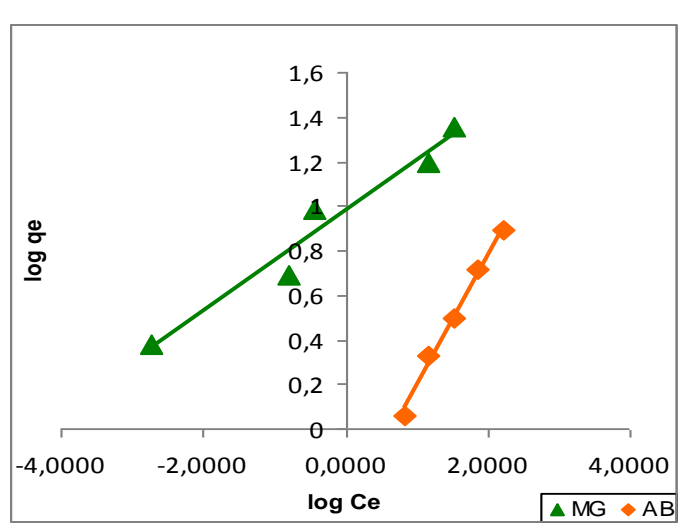

Figure 7b. The Linearized Freundlich isotherm of MG and AB161 uptake by waste waste marble dust

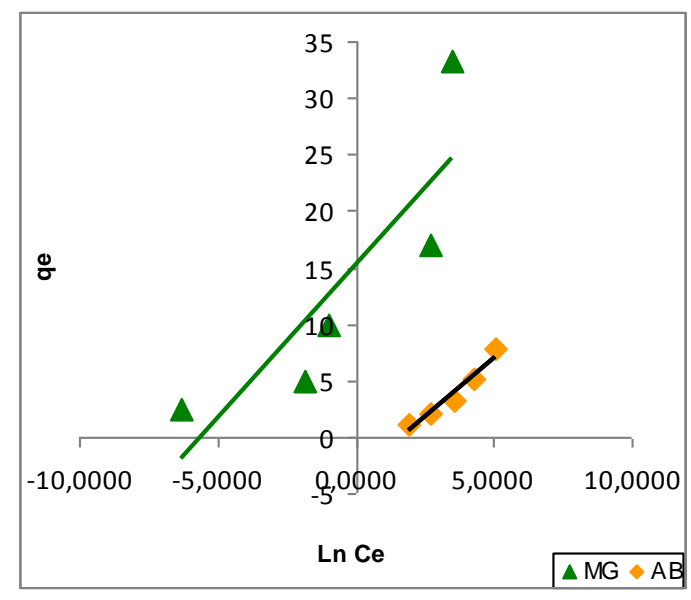

Figure 7c. The Linerized Temkin isotherm of MG and AB 161 uptake by waste waste marble dust 
The $n$ values between 1 and 10 (i.e., $1 / \mathrm{n}$ less than 1 ) indicate the beneficial adsorption (Fig. 7b). A relatively $n<<1$ indicates that adsorption intensity is favorable over the entire range of concentrations studied, while $n>1$ means that adsorption intensity is favorable at high concentrations but much less at lower concentrations (Banu and Guclu, 2009; Zhao et al., 2008). For the adsorption of MG and AB 161 on waste waste marble dust, the $n$ values were above beneficial adsorption.

The derivation of the Temkin isotherm assumes that the fall in the heat of adsorption is linear rather than logarithmic, as implied in the Freundlich equation. Temkin isotherm model is given in Eq. (4):

$\mathrm{q}_{\mathrm{e}}=(\mathrm{RT} / \mathrm{b}) \ln A C_{\mathrm{e}}$

$\mathrm{q}_{\mathrm{e}}=\mathrm{B} \ln \mathrm{A}+\mathrm{B} \ln \mathrm{C}_{\mathrm{e}}$

where $B=\operatorname{lnRT} / b, q_{e}\left(\mathrm{mg} \mathrm{g}^{-1}\right)$ and $C_{e}\left(\mathrm{mg} \mathrm{l}^{-1}\right)$ are the amounts of adsorbed dye per unit weight of adsorbent and unadsorbed dye concentration in solution at equilibrium, respectively. Also, $T$ the absolute temperature in $\mathrm{K}$ and $\mathrm{R}$ is the universal gas constant, $8.314 \mathrm{~J} \mathrm{~mol}^{-1} \mathrm{~K}^{-1}$. The constant $\mathrm{B}$ is related to the heat of adsorption (Fig. 7c).

\subsection{Adsorption kinetics}

Pseudo-second-order kinetics may be expressed as given by Eq. 6:

$\frac{d q_{t}}{d_{t}}=k_{2}\left(q_{e}-q_{t}\right)^{2}$

where $k_{2}$ is the rate constant of adsorption, $\mathrm{q}_{\mathrm{e}}$ and $\mathrm{q}_{\mathrm{t}}$ are the amount adsorbed at equilibrium (mg g $\left.{ }^{-1}\right)$. Integrating this for the boundary conditions $t=0$ to $t=t$ and $q_{t}=0$ to $q_{t}=q_{t}$ gives (Eq. 7 ):

$\frac{1}{\left(q_{e}-q_{t}\right)}=\frac{1}{q_{e}}+k_{2} t$

which is the integrated rate law for a pseudo-second-order reaction. Eq. (7) can be rearranged to obtain (Eq. 8):

$q_{t}=\frac{t}{\left(1 / k_{2} q_{e}^{2}\right)+\left(t / q_{e}\right)}$

which has a linear form of (Eq. 9)

$\frac{1}{q_{t}}=\frac{1}{k_{2} q_{e}{ }^{2}}+\frac{1}{q_{e}} t$

where $k_{2}$ was the rate constant of second-order MG and AB 161 adsorption. Fig. 8a shows the linear plots of $\mathrm{t} / \mathrm{q}_{\mathrm{t}}$ versus $t$. The correlation coefficients for the second-order kinetic model were higher than 0.999 indicating the applicability of this kinetic model of the adsorption process of MG and AB 161 on waste waste marble dust .

The rate parameter for intraparticle diffusion equation is given using the following equation (Ofomaja, 2008; Zhao et al., 2008) (Eq. 10).

$\mathrm{q}_{\mathrm{t}}=\mathrm{k}_{\mathrm{id}} \mathrm{t}^{1 / 2}+\mathrm{C}$

where $\mathrm{C}$ is the intercept and $k_{i d}$ is the intra-particle diffusion rate constant $\left(\mathrm{mg} \mathrm{g}^{-1} \mathrm{~min}^{1 / 2}\right.$ ). The plot $q$ versus $t^{1 / 2}$ is given by multiple linear regions representing the external mass transfer followed by intraparticle or pore diffusion. In this model, due to the porous nature of the adsorbent, pore diffusion is expanded to be surface adsorption (Karagöz et al., 2008). Fig. 8b exhibits the intra-particle diffusion model of MG and $A B 161$ adsorpsion on waste waste marble dust. The intra-particle diffusion rate constants $\mathrm{k}_{\mathrm{id}}$ and correlation coefficients are presented in Table 4.

The Elovich equation has general application to chemisorption kinetics. This equation has been applied satisfactorily to some chemisorption data and has been found to cover a large range of slow adsorption. The Elovich equation is often valid for systems in which the adsorbing surface is heterogeneous. The rate parameter for the Elovich equation is determined as (Sprynskyy, et al. 2005; Cheung et al. 2000). 
$q_{t}=\beta \ln (\alpha)+\beta \ln t$

where $\alpha\left(\mathrm{mgg}^{-1} \mathrm{~min}^{-1}\right)$ and $\beta\left(\mathrm{gmg}^{-1}\right)$ are the equilibrium rate constants for Elovich model. The equation constants can be obtained from the slope and intercept of a straight-line plot of $q_{t}$ against $\ln t$. The values of constants can be obtained from the slope and intercept of the plots (Fig. 8c). The values of kinetic constants are presented in Table 4.

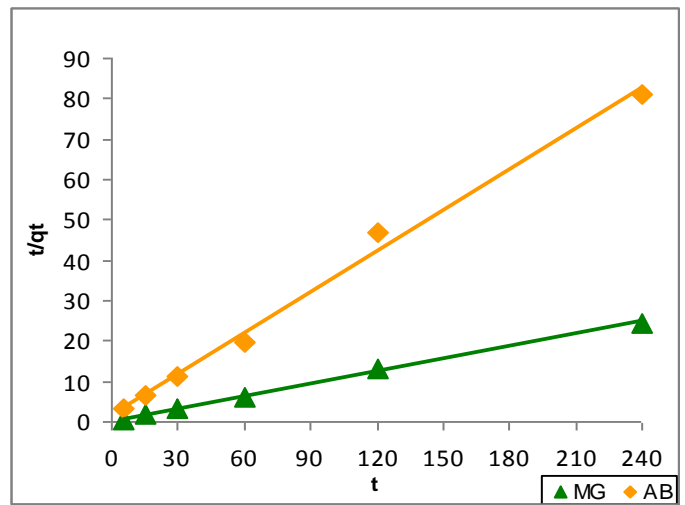

Figure 8a. Linerized pseudo-second-order kinetics plots for MG and $A B 161$ adsorption

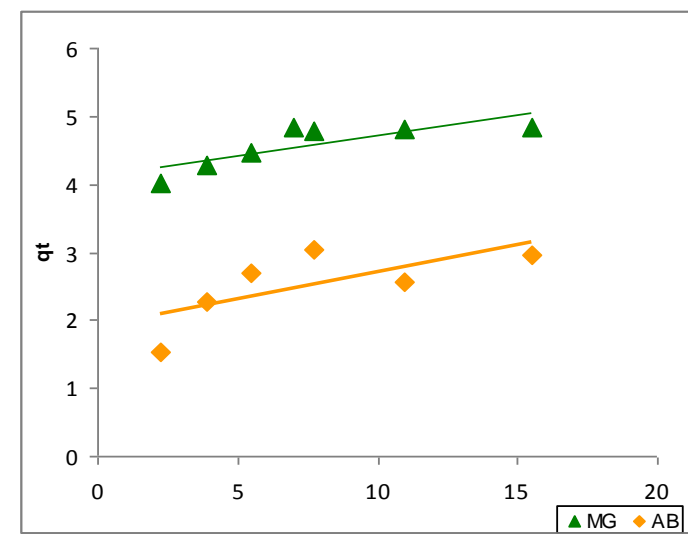

Fig.8b. Linerized intraparticle diffusion kinetics plots for $M G$ and $A B 161$ adsorption

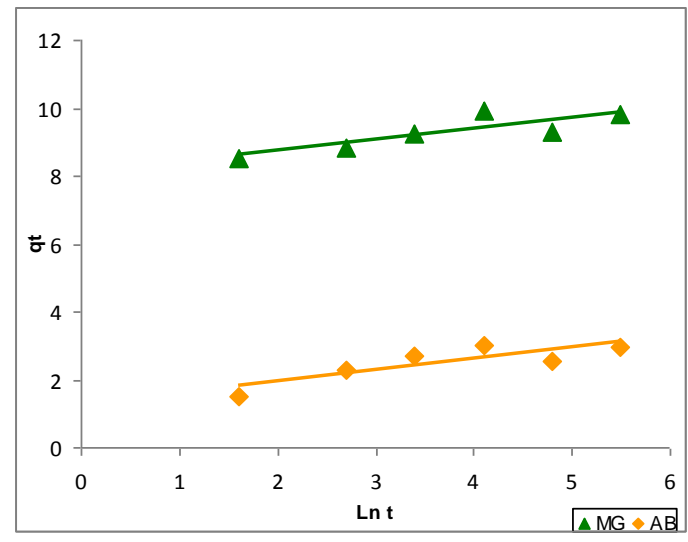

Fig. 8c. Linerized Elovich kinetics plots for MG and AB 161 uptake by waste waste marble dust

Table 4 . The kinetics constants for the removal of the MG and AB 161 by waste waste marble dust

\begin{tabular}{ccccccccccc}
\hline & \multicolumn{3}{c}{ Pseudo Second Order } & \multicolumn{2}{c}{ Intraparticle Diffusion } & \multicolumn{3}{c}{ Elovich } \\
\cline { 2 - 11 } Dye & $\mathbf{q}_{\mathbf{e}}$ & $\mathbf{k}_{\mathbf{2}}$ & $\boldsymbol{R}^{\mathbf{2}}$ & $\mathbf{C}$ & $\mathbf{k}_{\text {id }}$ & $\boldsymbol{R}^{\mathbf{2}}$ & $\boldsymbol{\beta}$ & $\boldsymbol{\alpha}$ & $\boldsymbol{R}^{\mathbf{2}}$ \\
\hline MG & 9.80 & 0.061 & 0.9992 & 4.133 & 0.059 & 0.6448 & 0.32 & $6.6 .10^{4}$ & 0.7329 \\
AB 161 & 2.96 & 0.689 & 0.9937 & 1.900 & 0.079 & 0.5008 & 0.33 & 47.07 & 0.7189 \\
\hline
\end{tabular}

\subsection{Thermodynamic parameters}

The adsorption standard free energy changes $\left(\Delta G^{\circ}\right)$ are determined with the following equation (Alpat, S.K. et. al., 2008; Lin J.X. et al,. 2008)

$\Delta G^{\circ}=-R T \ln K$

where $R$ is the gas constant $\left(8.314 \times 10^{-3} \mathrm{~kJ} \mathrm{~K}^{-1} \mathrm{~mol}^{-1}\right), \mathrm{T}$ is the temperature (K), and $\Delta \mathrm{G}^{\circ}$ is the free energy of sorption. The equilibrium constant was calculated from:

$\mathrm{K}=\mathrm{q}_{\mathrm{e}} / \mathrm{C}_{\mathrm{e}}$ 
where $\mathrm{q}_{\mathrm{e}}$ and $\mathrm{C}_{\mathrm{e}}$ were the equilibrium concentrations of malachite greenin solution and on the sorbent correspondingly.

The sorption distribution coefficient may be expressed in terms of enthalpy and entropy changes as a function of temperature:

$\ln \mathrm{K}=-\Delta \mathrm{H}^{\circ} / \mathrm{RT}+\Delta \mathrm{S}^{\circ} / \mathrm{R}$

The enthalpy change $\left(\Delta \mathrm{H}^{\circ}\right)$ and the entropy change $\left(\Delta \mathrm{S}^{\circ}\right)$ can be calculated from a plot of InK versus $1 / T$.

The values obtained were given in Table 5 . The endothermic nature of process is well explained by positive value of the enthalpy change. The negative value of free energy suggests that the adsorption process is spontaneous and the affinity of the adsorbent for the dye is indicated by the positive value of entropy.

Table 5. Thermodynamic coefficients for $M G$ and $A B 161$ adsorption on waste waste marble dust

\begin{tabular}{|c|c|c|c|c|c|c|c|}
\hline \multirow{2}{*}{ Dye } & \multicolumn{4}{|c|}{$\Delta \mathrm{G}^{\circ}\left(\mathrm{kJ} \mathrm{mol}^{-1}\right)$} & \multirow{2}{*}{$\Delta \mathbf{H}^{\circ}$} & \multirow{2}{*}{$\left(\mathrm{kJ} \mathrm{mol}{ }^{-1}\right)$} & \multirow{2}{*}{$\Delta \mathrm{S}^{\circ}(\mathrm{kJ} \mathrm{mol})^{-1} \mathrm{~K}^{-1}$} \\
\hline & $20^{\circ} \mathrm{C}$ & $30^{\circ} \mathrm{C}$ & $50^{\circ} \mathrm{C}$ & $70^{\circ} \mathrm{C}$ & & & \\
\hline MG & -14.36 & -15.87 & -18.51 & -19.31 & & 15.376 & 0.102 \\
\hline AB 161 & -2.69 & -3.27 & -3.81 & -4.61 & & 7.977 & 0.036 \\
\hline
\end{tabular}

\subsection{The Results of the ANN Modeling}

The developed ANN model had three layers. The input layers had four neurons as contact time, marble sludge dust amount, initial dye concentration and temperature. The output had one neuron as percentage of the adsorption efficiency for the removal malachite green and acid blue 161 dyes by marble sludge dust. Fig. 9 shows the number of neurons in the two hidden layers. It was selected as 12 neurons because of its minimum error values (\%) for training and testing sets.

The ranges of operating variables were initial concentration (12.5-200 $\left.\mathrm{mg} \mathrm{I}^{-1}\right)$, contact time (5-240 min), temperature $\left(20-70{ }^{\circ} \mathrm{C}\right)$, and absorbent dosage $\left(0.0625-1 \mathrm{~g}^{-1}\right)$. The data were divided into training, validation, and sets. All samples were to be scaled into the $0-1$ due to using sigmoid transfer function in the output layer. A regression analysis to show the performance of the network is given Fig. 10.

The performance of the constructed ANN model was also statistically measured by mean squared error (MSE) and the coefficient of determination $\left(R^{2}\right)$ as follows:

MSE $=\left(\frac{1}{n} \sum_{i=1}^{n}\left(y_{i}-y_{d i}\right)^{2}\right)$

$R^{2}=1-\frac{\sum_{i=1}^{n}\left(y_{i}-y_{d i}\right)^{2}}{\sum_{i=1}^{n}\left(y_{d i}-y_{m}\right)^{2}}$

where $\mathrm{n}$ is the number of points, $\mathrm{y}_{\mathrm{i}}$ is the predicted value, $\mathrm{y}_{\mathrm{di}}$ is the actual value, and $\mathrm{y}_{\mathrm{m}}$ is the average of the actual values.

The prediction model was shown that the ANN model was able to predict the adsorption efficiency for the removal malachite green and acid blue 161 dyes by marble sludge dust with $R>0.89$ and $\mathrm{MSE}<0.01$. These results are quite reasonable and accepted. 


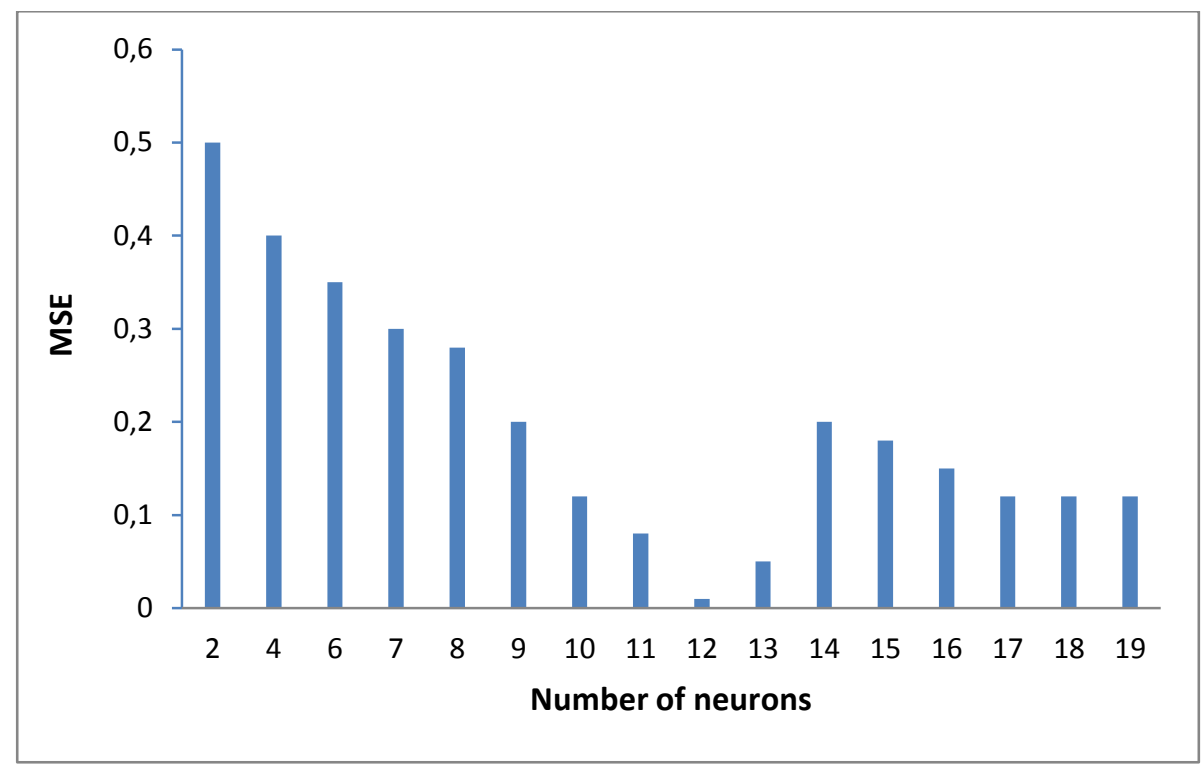

Figure 9. The number of hidden layer neurons in the ANN structure
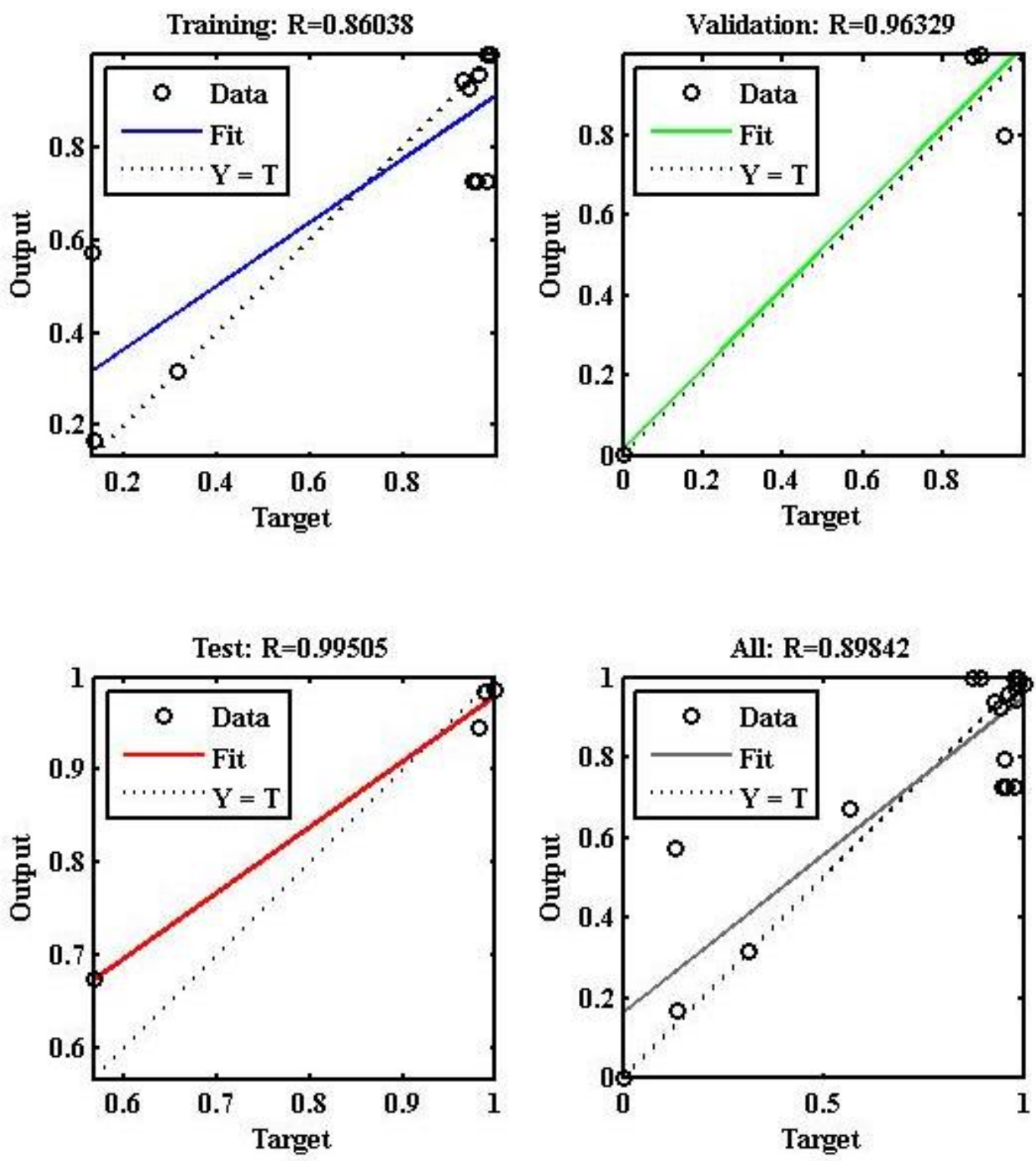

Figure 10. Performance of the ANN model 


\section{Conclusions}

The effect of various operational parameters such as contact time, waste marble dust amount, initial dye concentration and temperature on teh adsorption of malachite green and acid blue 161 dyes was investigated and optimized. The waste marble dust used as a low-cost adsorbent showed a excellent adsorption performance for removal of malachite green dye from aqueous solutions. The maximum adsorption capacity of waste waste marble dust was found to be $33.23 \mathrm{mg} \mathrm{g}^{-1}$ for $200 \mathrm{mg} \mathrm{I}^{-1} \mathrm{MG}$ dye concentration and $7.77 \mathrm{mg} \mathrm{g}^{-1}$ for $200 \mathrm{mg} \mathrm{l}^{-1} A B$ 161.The adsorption of the basic dye (MG) was better than the adsorption on an acidic dye $(A B)$ on waste foundry sand. ANN model was used some experimental data to predict the response of the experiments at new similar conditions for the problem of malachite green and acid blue 161 dyes removal by waste marble dust. The proposed ANN modelling method also decreases the number of the experiments to remove of the adsorption efficiency for the removal of malachite green and acid blue 161 dyes by waste marble dust. This decreases the cost of the experimental studies.

\section{References}

Aber S., Amani-Ghadim A.R. and Mirzajani V. (2009), Removal of $\mathrm{Cr}$ (VI) from polluted solutions by electrocoagulation: Modeling of experimental results using artificial neural network, Journal of Hazardous Materials, 171, 484-490.

Ahlawat R., Srivastava V.C., Mall I.D. and Sinha S. (2008), Investigation of the electrocoagulation treatment of cotton blue dyes solution using aluminium electrode, Clean-Soil Air Water, 36(10-11), 863-869.

Ahmad M.A. and Alrozi R. (2011), Removal of malachite green dye from aqueous solution using rambutan peelbased activated carbon: Equilibrium, kinetic and thermodynamic studies, Chemical Engineering Journal, 171, 510- 516.

Alpat S.K., Ozbayrak O., Alpat Ş. and Akçay H. (2008), The adsorption kinetics and removal of cationic dye, Toluidine Blue O, from aqueous solution with Turkish zeolite, Journal Hazardous Materials, 151, 213-220.

Alver E. and Metin A.U. (2012), Anionic dye removal from aqueous solutions using modified zeolite: Adsorption kinetics and isotherm studies, Chemical Engineering Journal, 200-202, 59-67.

Bacarji E., Toledo Filho R.D., Koenders E.A.B., Fiqueiredo E.P. and Lopes J.L.M.P. (2013), Sustainability perspective of marble and granite residues as concrete, Construction and Building Materials, 45, 1-10.

Baek M.H., Ijagbemi C.O., O S.J. and Kim D.S. (2010), Removal of Malachite Green from aqueous solution using degreased coffee bean, Journal of Hazardous Materials, 176, 820-828.

Banu T. and Güçlü G. (2009), Removal of basic dyes from aqueous solutions using natural clay, Desalination, 249, 1377-1379.

Bulut E., Ozacar M. and Sengil I.A. (2008), Adsorption of malachite green onto bentonite: Equilibrium and kinetic studies and process design, Microporous and Mesoporous Materials, 115, 234-246.

Celik M.Y. and Sabah E. (2008), Geological and technical characterisation of Iscehisar (Afyon-Turkey) marble deposits and the impact of marble waste on environmental pollution, Journal of Environmental Management, 87, 106-116.

Cheung C.W., Porter J.F. and McKay G. (2000), Elovich equation and modified second-order equation for sorption of cadmium ions onto bone char, Journal of Chemical Technology and Biotechnology, 75,963-970.

Crini G. (2006), Non-conventional low-cost adsorbents for dye removal: a review, Bioresource Technology, 97, 1061-1085.

Dawood G.S. (2010), Removal Orange (G) Dye from aqueous solution by adsorption on Bentonite, Tikrit Journal of Pure Science, 15(1), 231-234.

Elemen S., Kumbasar P.E. and Yapar S. (2012), Modeling the adsorption of textile dye on organoclay using an artificial neural network, Dyes and Pigments, 95(1), 102-111.

Gencel O., Ozel C., Koksal F., Erdogmus E., Martínez-Barrerae G. and Brostow W. (2012), Properties of concrete paving blocks made with waste marble, Journal of Cleaner Production, 21, 62-70.

Haykin S. (1999), A Comprehensive Foundation, 2nd Ed., Prentice Hall International, Inc., Canada. 
Hui K.S., Chao C.Y.H. and Kot S.C. (2005), Removal of mixed heavy metal ions in wastewater by zeolite 4A and residual products from recycled coal fly ash, Journal of Hazardous Materials, 127(1-3), 89-101.

Jayaraj R., Jeyasingh Thanaraj P., Thillai Natarajan S. and Martin Deva Prasath P. (2011), Removal of congo red dye from aqueous solution usin acid activated ecofiriendy low cost carbon prepared from marine algae valoria bryopsis, Journal of Chemical and Pharmaceutical Research, 3(3), 389-396.

Karagöz S., Tay T., Uçar S. and Erdem M. (2008), Activated carbons from waste biomass by sulfuric acid activation and their use on methylene blue adsorption, Journal of Hazardous Materials, 99, 6214-6222.

Kuleyin A. and Aydin F. (2011), Removal of reactive textile dyes (Remozal Brillant Blue R and Remozal Yellow) by surfactant-modified natural zeolite, Environmetal Progress and Sustainable Energy, 30, 141-151.

Lian L., Guo L. and Wang A. (2009), Use of $\mathrm{CaCl}_{2}$ modified bentonite for removal of Congo red dye from aqueous solutions, Desalination, 249, 797-801.

Lin J.X., Zhan S.L, Fang M.H., Qian X.Q. and Yang H. (2008), Adsorption of basic dye from aqueous solution on fly ash, Journal of Environmental Management, 87, 193-200.

Luo P., Zhao Y., Zhang B., Liu J., Yang Y. and Liu J. (2010), Study on the adsorption of Neutral Red dye from aqueous solution onto halloysite nanotubes, Water Resource, 44, 1489-1497.

Mahmoued E.K. (2010), Cement kiln dust and coal filters treatment of textile industrial effluents, Desalination, 255, 175-178.

Nethaji S., Sivasamy A., Thennarasu G. and Saravanan S. (2010), Adsorption of Malachite Green dye onto activated carbon derived from Borassus aethiopum flower biomass, Journal of Hazardous Materials, 181 271-280.

Nuhoglu Y., Malkoc E., Dundar M. (2006), Adsorption of chromium (VI) on pomace-an olive oil industry waste: batch and column studies, Journal of Hazardous Materials, 138, 142-151.

Ofomaja A.E. (2008), Kinetics study and sorption mechanism of methylene blue and methyl violet onto mansonia (Mansonia altissima) wood sawdust, Chemical Engineering Journal, 143, 85-95.

Oren A.H. and Kaya A. (2006), Factors affecting adsorption characteristics of $\mathrm{Zn}^{2+}$ on two natural zeolites, Journal of Hazardous Materials, 131(1-3), 59-65.

Prakash N., Manikandan S.A., Govindarajan L. and Vijayagopal V. (2008), Prediction of biosorption efficiency for the removal of copper(II) using artificial neural networks, Journal of Hazardous Materials, 152, 1268-1275.

Rahman A., Urabe T. and Kishimoto N. (2013), Color removal of reactive procion dyes by clay adsorbents, Procedia Environmental Sciences, 17, $270-278$.

Raj K.R., Kardam A., Arora J.K., Srivastava M.M. and Srivastava S. (2010), Neural Network Modeling for Ni(II) removal from aqueous system using shelled moringa oleifera seed powder as an agricultural waste, Journal of Water Resource and Protection, 2(4), 331-338.

Rastogi K., Sahu J.N., Meikap B.C. and Biswas M.N. (2008), Removal of methylene blue from wastewater using fly ash as an adsorbent by hydrocyclone, Journal of Hazardous Materials, 158, 531-540.

Sadrzadeh M., Mohammadi T., Ivakpour J. and Kasiri N. (2008), Separation of lead ions from wastewater using electrodialysis: Comparing mathematical and neural network modeling, Chemical Engineering Journal, 144, 431-441.

Sinha K., Saha P.D. and Datta S. (2012), Response surface optimization and artificial neural network modeling of microwave assisted natural dye extraction from pomegranate rind, Industrial Crops and Products, 37(1), 408-414

Sprynskyy M., Lebedynets M., Terzyk A.P., Kowalczyk P., Namieśnik J. and Buszewski B. (2005), Ammonium sorption from aqueous solutions by the natural zeolite Transcarpathian clinoptilolite studied under dynamic conditions, Journal Colloid Interface Science, 284(2), 408-415.

Thinakaran N., Baskaralingam P., Thiruvengada Ravi K.V., Panneerselvam P. and Sivanesan S. (2006), Adsorptive removal of acid blue 15: equilibrium and kinetic study, Clean-Soil Air Water, 36(9), 798-804.

Yetilmezsoy K. and Demirel S. (2008), Artificial neural metwork (ANN) approach for modeling of Pb (II) adsorption from aqueous solution by Antep pistachio (Pistacia vera L.) shells, Journal of Hazardous Materials, 153, 1288-1300.

Zhao M., Tang Z. and Liu P. (2008), Removal of methylene blue from aqueous solution with silica nano-sheets derived from vaemiculite, Journal of Hazardous Materials, 158, 43-51. 